\title{
A mis hijos los educo yo: Reflexiones en torno a una manifestación política conservadora en Costa Rica
}

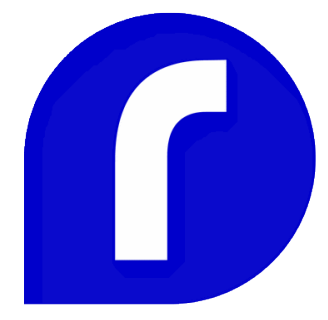

Recibido: 29 de junio de 2021 Revisado: 1 de septiembre de 2021 Aprobado: 30 de septiembre de 2021

Sindy Mora Solano Socióloga. Máster en Derechos Humanos y Educación para la Paz. Es investigadora del Instituto de Estudios Sociales en Población (IDESPO) de la Universidad Nacional (Costa Rica), investigadora del Instituto de Investigaciones Sociales (IIS) de la Universidad de Costa Rica (Costa

Rica) y docente en la Escuela de Sociología de esta misma universidad. Trabaja temas relacionados con acciones colectivas, movimientos sociales, memoria de luchas populares, procesos de construcción de resistencias políticas y

conservadurismo político. Es autora del libro La política de la calle. Organización y autonomía en la Costa Rica contemporánea, publicado en San José, Costa Rica, por la Editorial de la Universidad

de Costa Rica, en el año 2016. Correo electrónico: sindy.mora.solano@una.ac.cr ORCID: 0000 0001 6784 5532
Resumen: En este artículo se estudia la manifestación política llamada $A$ mis hijos los educo yo, realizada en San José, Costa Rica, en el año 2017. Esta protesta social es una muestra de las distintas expresiones del conservadurismo en oposición a las políticas de educación sexual, a cargo del Ministerio de Educación Pública (MEP) del Gobierno de Costa Rica. Asimismo, esta manifestación da cuenta de las discusiones posicionadas, posteriormente, durante la campaña electoral del 2017-2018. En el artículo se estudia el contexto y las principales características de esta manifestación.

Palabras clave: Protesta social, educación sexual, conservadurismo político, familia

\section{Educate my Children: Discussions about a Conservative Political Demonstration in Costa Rica}

Abstract: This article studies the political demonstration called I educate my children, held in San José, Costa Rica, in 2017. This social protest is a sample of the different expressions of political conservatism in opposition to sexual education policies, in charge of the Ministry of Public Education (MEP) of the Government of Costa Rica. At the same time, this demonstration gives an account of the discussions that took place during the 2017-2018 electoral campaign. The article studies the context and the main characteristics of this demonstration.

Key words: Social protest, sex education, political conservatism, family

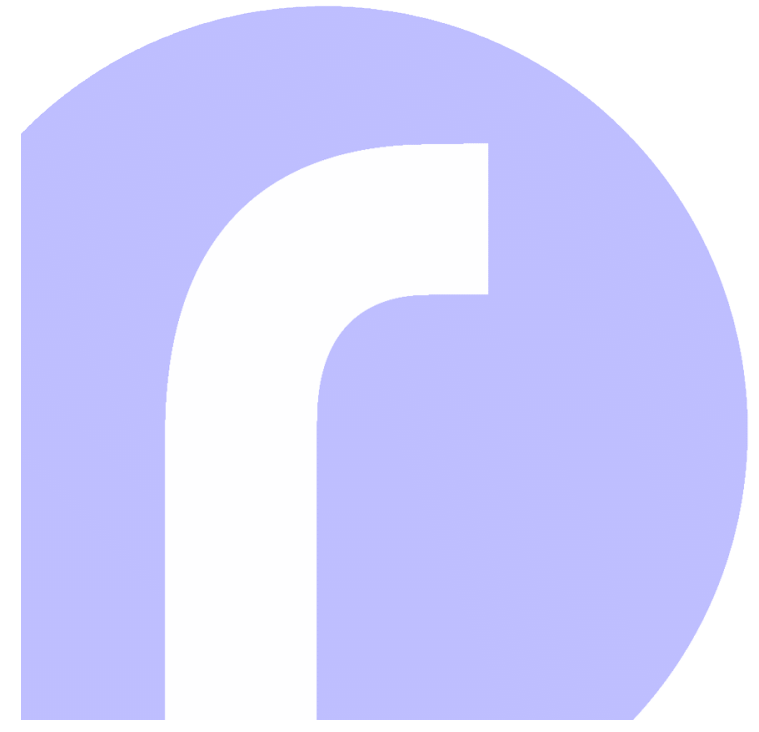

https://revistas.uned.ac.cr/index.php/rupturas cc) (i) (2)
Rev. Rupturas 12(1), Costa Rica, Ene-Jun 2022. ISSN 2215-2466. pp 1-26. 


\section{Introducción}

En este artículo se analiza la movilización política $A$ mis hijos los educo yo, realizada el 22 de julio de 2017, en la Plaza de la Democracia, en San José, Costa Rica. Esta manifestación fue convocada ante la entrada en vigencia del Programa de Estudio de Afectividad y Sexualidad Integral, que el Ministerio de Educación Pública (MEP) del Gobierno de Costa Rica empezó a impartir en el año 2018 (Ministerio de Educación Pública (MEP) 2017).

De acuerdo con declaraciones de Sonia Marta Mora, ministra de Educación Pública de la administración de Luis Guillermo Solís Rivera (2014-2018) (Avendaño 2017), las Guías para la Afectividad y la Sexualidad, que son la base de este proceso educativo, fueron construidas a partir de los datos obtenidos tras la ejecución y análisis de los resultados de la Segunda Encuesta Nacional de Salud Sexual y Reproductiva Costa Rica, 2015 (Ministerio de Salud 2016). Los datos recolectados a través de la encuesta evidenciaron una serie de carencias en cuanto a la educación sexual de las personas consultadas, lo que permitió al Gobierno dar impulso a una política que ha sido fuente de una serie de conflictos en el país.

La movilización política $A$ mis hijos los educo yo, también conocida por la consigna Con Mis Hijos No Te Metas, se inscribió en una serie de manifestaciones políticas realizadas en distintos países de América Latina, bajo la convocatoria de lucha contra la llamada ideología de género. En los últimos años se ha producido una abundante literatura sobre los actores políticos articulados en contra de la ideología de género, sus proyectos políticos, sus formas organizativas y las distintas manifestaciones que han protagonizado.

De esta manera, los estudios disponibles han analizado las alianzas entre líderes religiosos y políticos, tanto católicos como evangélicos, con el fin de impedir el reconocimiento de los derechos de las mujeres y de la población LGTBIQ (Cunha 2017; Da Silva et al. 2018; Fuentes 2018; Arguedas 2010; 2020; Santos Serejo y Cal 2021). Asimismo, se han estudiado las expresiones conservadoras en los discursos y redes sociales de políticos, en particular, de diputados católicos y evangélicos (Portantiolo Maia, Bittencourt, y Rodrigues 2017; Arce 2017). De la misma manera, se ha analizado la intervención de las jerarquías de la iglesia católica y de diputadas y diputados de bancadas conservadoras en los programas de educación pública (Fontelas 2015; Romancini 2018; Morán Faúndes 2019; De Carvalho y Luiz Polizel 2018; Jung Mo Sung 2015).

En el tema particular de las movilizaciones políticas conservadoras y, en específico, de la manifestación $A$ mis hijos los educo yo, destacan los estudios realizados para los casos de Colombia, Ecuador, México y Perú (Meneses 2019; Ribeiro 2019; González et al. 2018). Esta literatura coincide en que el fenómeno del conservadurismo político surge de la alianza entre actores reli- 
giosos anteriormente concebidos como antagónicos: los católicos y los evangélicos. Estos, con una fuerte presencia en los medios de comunicación y en los parlamentos, han incidido en la construcción de las agendas públicas vinculadas a la educación sexual de distintos países latinoamericanos, por lo que esta literatura reconoce el carácter transnacional de este movimiento conservador.

De la misma manera, estas investigaciones apuntan al miedo y al pánico moral como elementos centrales de la articulación del conservadurismo político. La utilización del miedo y del pánico moral no se ha circunscrito a los derechos sexuales y reproductivos, ya que estos actores se han posicionado en temáticas que los vinculan con el conservadurismo económico de la derecha política de sus respectivos países. Ejemplos de lo señalado son el posicionamiento de los actores políticos conservadores en el plebiscito por la firma de los acuerdos de paz entre el Gobierno de Colombia y las FARC, celebrado en el año 2016, y la injerencia de estos actores en el impeachment contra Dilma Rouseff, presidenta de Brasil entre los años 2011 y 2016 (González y Castro 2018; De Carvalho y Luiz Polizel 2018).

Este trabajo se compone de tres apartados adicionales a esta breve introducción. En el primero de ellos se presenta una discusión teórica y metodológica para comprender este tipo de movilizaciones. En el segundo se expone el contexto y las principales características de la convocatoria y la manifestación $A$ mis hijos los educo yo. Finalmente, se presentan algunas conclusiones sobre el tema de estudio.

\section{Consideraciones de carácter teórico y metodológico}

Ana María Fernández ha estudiado cómo los procesos de objetivación y subjetivación de la modernidad se encuentran estructurados en función de una "lógica atributiva, binaria y jerárquica" (Fernández 2009, 45) de las sexualidades. Esto significa que, a pesar de que históricamente el ser humano ha tenido prácticas sexuales que se han instaurado fuera de esta lógica, en la modernidad nos encontramos en un escenario en donde las sexualidades se estructuran jerárquicamente a partir del binarismo hombre-mujer.

De acuerdo con esta autora, si bien la homofilia en la antigua Grecia no puede comprenderse como sinónimo de la expresión moderna de la homosexualidad, dado que, la clave de esta sexualidad era "hacerse servir" (Fernández $2009,168)$ de esclavos jóvenes, tanto hombres como mujeres, sí se puede afirmar que en dicho periodo existían prácticas sexuales que se encontraban más allá de una lógica binaria. Fue con la modernidad que la sexualidad se entretejió con la noción cristiana de contranatura, a partir de la cual los placeres sexuales quedaron enmarcados en la reproducción sexual. De allí surgió la idea de "un solo Dios, una sola iglesia, una única sexualidad" (Fernández 2009, 171).

Posteriormente, con el desarrollo del capitalismo, la sexualidad se construyó en vínculo con el Estado, con el apoyo de disciplinas como la medicina, la 
psicología y la psiquiatría. En este escenario, aparecieron las anormalidades sexuales, encarnadas en figuras como "la mujer histérica, el niño masturbador, la pareja malthusiana y adulto perverso" (Fernández 2009, 174). De allí que, en este periodo, la homosexualidad y el homosexual se convirtieron en el otro. Por supuesto, este proceso no se dio sin resistencias, por lo que, a partir de la segunda mitad del siglo XX, surgieron una serie de movimientos sociales que han cuestionado esta lógica atributiva, binaria y jerárquica de las sexualidades.

Fernández ha expuesto los mecanismos de objetivación y subjetivación de los seres construidos como hombres y mujeres, con el fin de conformar subjetividades sexualizadas y disciplinadas. No obstante, y siguiendo a Deleuze, frente a esta lógica atributiva, binaria y jerárquica de las sexualidades, la autora plantea la necesidad de pensar en la multiplicidad y no en la diferencia, al entender por multiplicidad a "aquello que escapa a dualismos y binarismos generalmente reductivos, que incita a pensar desde lógicas no disyuntivas, desde el «y» y el «entre»" (Fernández 2009, 185).

En este mismo sentido, Judith Butler ha planteado que el vínculo sexo-género, tal y como fue interpretado en los primeros análisis realizados por feministas, posibilitó la idea de que solo podían existir dos géneros (Butler 2007). Incluso, el posicionamiento de algunas feministas potenció la tesis de que el sexo no es culturalmente construido (la fórmula sería: sexo=biología y género=construcción social), a pesar de que la autora concibe el sexo y el género como construcciones culturales. Para Butler, es central la tesis de la performatividad del género, que pone de manifiesto que "lo que consideramos una esencia interna del género se construye a través de un conjunto sostenido de actos, postulados por medio de la estilización del cuerpo basada en el género" (Butler 2007, 17).

Esta tesis, para decirlo en palabras de Fernández, rompe con la lógica atributiva, binaria y jerárquica de las sexualidades, con el fin de plantear el género más allá de la metafísica de la sustancia que ha marcado los debates de la historia del pensamiento filosófico. De esta manera, superar dicha metafísica permitiría formular preguntas, en donde puedan ser y sean concebidos como humanos aquellos cuerpos y sexualidades no inscritos en las lógicas hegemónicas. Estos cuestionamientos permiten posicionar la idea de la construcción de un mundo en constante disputa entre una concepción que parte de la dualidad sexo-género, por un lado, frente a la alternativa señalada por Butler de abrir las posibilidades del género, con las condiciones que permitan la vida de todas las sexualidades y corporeidades.

El aporte teórico de estas estudiosas a los argumentos que se exponen seguidamente radica en que ayudan a dilucidar el marco cultural en el que se posiciona una demanda política como la expresada en una movilización bajo la consigna $A$ mis hijos los educo yo. Como se expone a continuación, en las manifestaciones realizadas por los actores políticos conservadores se puede observar cómo la lógica atributiva, binaria y jerárquica de las sexualidades, de la que habla Fernández, articula un discurso en donde la palabra divina y 
los textos bíblicos son parte fundamental de la estructuración de la vida social y de las sexualidades. En dichas manifestaciones, el término contranatura se encuentra vigente para designar todo aquello que escapa a la multiplicidad. En este marco es en donde adquiere sentido la oposición a una educación sexual que es concebida como no reproductora de la normatividad de los sexos.

Desde la perspectiva de estos actores políticos, la educación sexual debe respetar el orden jerárquico Dios-iglesia-familia, en el cual el Estado no tiene ninguna cabida y en donde se concibe que el individuo no debe tener la autonomía para ejercer su género. Como apunta Fernández, en este caso es necesario pensar la subjetividad desde la sumisión, de la familia y de la mujer, en primer lugar, pero, fundamentalmente, la de los hijos e hijas que, se supone, nada tienen que aportar respecto a su educación y su sexualidad. De esta forma, el "disciplinamiento no se logra sólo a través de la manera en que los integrantes de una sociedad piensan, sienten y actúan, sino también marcando sus cuerpos" (Fernández 2009, 56), por ello, estas manifestaciones políticas pueden comprenderse como estrategias públicas de disciplinamiento de los cuerpos.

En consideración de lo expuesto, en este artículo los actores políticos conservadores son comprendidos, con la propuesta de Geoffrey Pleyers, como movimientos sociales conservadores (Pleyers 2019). Si bien el concepto de movimientos sociales históricamente ha sido asociado al progresismo y a la defensa de los derechos humanos, los actores políticos conservadores pueden ser escudriñados bajo esta herramienta analítica, ya que tienen a disposición una serie de recursos (McCarthy y Zald 1977), que permiten su comprensión en el escenario de negación de los derechos de los otros. De esta manera, con los recursos políticos disponibles, estos actores han logrado articular un discurso que tiene resonancia en distintos grupos sociales; han posicionado este discurso en el escenario político, debido a su acceso a distintos medios de comunicación; con sus agendas políticas han logrado incidir en la toma de decisiones, mediante la estrategia de las alianzas, del lobby político o de la formación de figuras políticas particulares; y, finalmente, tienen un proyecto político estructurado que trasciende la discusión de los derechos sexuales y reproductivos.

El presente artículo realiza un análisis de la manifestación $A$ mis hijos los educo yo, con el objetivo de comprender los recursos movilizados en el acto político señalado. Desde esta perspectiva, este artículo propone mirar las imágenes que se presentan a continuación desde una tradición teórica feminista, que comprende que en el campo de la política se reproduce la lógica atributiva, binaria y jerárquica de las sexualidades, en el proceso de búsqueda de restarle humanidad a los cuerpos, sexualidades y performatividades que se escapan del binarismo.

Es importante señalar que todos los análisis disponibles en torno a la manifestación A mis hijos los educo yo, llevadas a cabo en distintos lugares de América Latina y señalados anteriormente, indagan en este tipo de acciones 
de protesta social sin haber participado directamente en las movilizaciones, a diferencia de lo que se propone en este artículo, que es el estudio de la manifestación política a través de su participación en ella. En ese sentido, este trabajo parte de una estrategia metodológica que busca superar la reconstrucción de la protesta mediante fuentes periodísticas o redes sociales, así como ir más allá de la memoria de la protesta, para avanzar en el análisis etnográfico de esta, distinción que ha sido planteada por el sociólogo argentino Javier Auyero (Auyero 2002; 2004).

Como se señaló en la introducción, la autora participó en la manifestación $A$ mis hijos los educo yo, realizada el 22 de julio de 2017, en la Plaza de la Democracia, en San José, Costa Rica. Esta concentración tuvo una duración de tres horas, ya que inició a las 9 de la mañana y finalizó a las 12 medio día. Durante esta manifestación se realizó una observación. Como suele suceder en distintas acciones colectivas de protesta, muchas personas asisten con sus cámaras fotográficas, lo que permitió a la autora tomar fotografías, algunas de las cuales se presentan a continuación. Dado que esta manifestación estuvo estructurada mediante discursos emitidos por distintos actores, tal y como se expone a continuación, la autora tomó nota de discursos y frases en su teléfono. Esta actividad se combinó con la toma de fotografías del evento.

Valga apuntar que la manifestación a la que se hace referencia tuvo una convocatoria abierta al público a través de redes sociales, en particular, bajo el perfil Concentración por la Familia Costarricense, de donde se han tomado algunas imágenes. Asimismo, esta manifestación se realizó en un espacio también público, lo que permitió la participación en esta. Todas las fotografías que se presentan a continuación fueron tomadas por la autora, como parte de su participación directa en esta manifestación.

\section{La manifestación A mis hijos los educo yo}

\section{El contexto}

Como ha señalado Córdova, las iglesias de corte evangélico han pasado por un amplio proceso de transformación, convirtiéndose en un actor político significativo de la región latinoamericana (Córdova 2014). De acuerdo con este autor, fue a partir de los años ochenta, en el contexto de la crisis económica mundial, que muchos sectores afectados por dicha crisis se incorporaron a estas iglesias, con el objetivo de buscar estabilidad emocional y unidad familiar. Este escenario potenció el surgimiento de partidos políticos de esta naturaleza y dio origen al ascenso de una élite evangélica que estaría compuesta por dos tendencias, como se reproduce en la siguiente cita:

Por un lado, los nuevos conversos evangélicos, especialmente de estratos altos, acostumbrados a la actividad po- 
lítica, conforman partidos que se presentan ante la sociedad como «la voz de los evangélicos» (pero en general sin votaciones significativas) [...] Por el otro, el voto evangélico de sectores populares sirve para consolidar relaciones clientelares entre actores políticos y líderes religiosos e incluir representantes en las listas de diversos partidos, como en Brasil, Perú o Guatemala. En este contexto se tiende a instrumentalizar el apoyo electoral evangélico a favor de los intereses más diversos (Córdova 2014, 116-17).

Un elemento por destacar es que, a pesar de que el discurso conservador ya estaba posicionado en los años sesenta y setenta en Estados Unidos, producto del accionar político de los movimientos por la diversidad sexual, fue hasta los años noventa que este discurso tomó fuerza, tanto en Estados Unidos como en la región latinoamericana. En esta década surgieron los movimientos denominados provida y profamilia, con el objetivo de presionar a las élites políticas para detener el avance de los derechos sexuales y reproductivos vinculados a las agendas de derechos de las mujeres y la diversidad sexual.

Córdova explica esta transformación a partir de dos procesos (Córdova 2014). El primero, ya se había acentuado el proceso de conversión evangélica en muchos países latinoamericanos, en el contexto de la crisis económica de los ochenta. El segundo, las conferencias de la Organización de las $\mathrm{Na-}$ ciones Unidas (ONU) de los años noventa, en particular, las conferencias sobre Población y Desarrollo de El Cairo (1994) y sobre Mujeres en Beijing (1995). Así, los derechos sexuales y reproductivos fueron determinantes para potenciar y relanzar un discurso y una práctica política que buscaba restaurar la familia nuclear heterosexual y afianzar el lugar tradicional de las mujeres (Lenine y Oncampo 2020). El carácter latinoamericano de estos procesos se puede observar en las marchas convocadas en defensa de la familia y en contra la educación sexual, de las cuales son una expresión las manifestaciones $A$ mis hijos los educo yo.

Para el caso costarricense, la conflictividad referida al tema de la educación sexual debe ubicarse en un escenario de conflictividades más amplio, en donde las disputas entre el Estado confesional y las demandas por un Estado Laico han sido determinantes. Como ha señalado Arguedas, el enfrentamiento entre los actores que participan y defienden el Estado confesional costarricense y las demandas de los movimientos feministas han sido y continúan siendo irreconciliables (Arguedas 2010). Una muestra de ello es que en los últimos procesos electorales ha sido frecuente el posicionamiento de una dis- 
cusión pública, en la que han dominado temas como la educación sexual, las uniones de personas del mismo sexo, el aborto, la anticoncepción oral de emergencia y la Fecundación In Vitro (FIV), entre otras (Díaz 2017).

De la misma forma, Fuentes ha analizado el proceso mediante el que los partidos políticos tradicionales han asumido los discursos y construyen alianzas con los partidos evangélicos, mientras que la población votante es movilizada en cuanto su condición de feligreses (Fuentes 2014). Estas alianzas se evidencian en procesos en donde las "autoridades católicas y evangélicas organizan conjuntamente manifestaciones nacionales por la vida y la familia, y contra el aborto y la homosexualidad, donde hace visible al "sujeto embrionario", comparándolo con el personaje de Jesús recién concebido" (Fuentes 2014, 28). Tanto Arguedas como Fuentes han dado cuenta de cómo estos actores defienden un orden jerárquico en el que no se cuestiona la violencia de género, por ejemplo, y se asume con todas sus implicaciones el control y la vigilancia del útero como un elemento fundamental de la vida política.

Es pertinente señalar, que no defender la lógica atributiva, jerárquica y binaria de las sexualidades implica ser considerado un antipatriota, dado que, en Costa Rica las identidades políticas históricamente fusionaron la defensa de la patria y la nacionalidad con la defensa de la familia (Quesada 2012). Es en este escenario que en Costa Rica ha adquirido sentido la polémica por los derechos sexuales y reproductivos de las mujeres, en particular, por el acceso a métodos de contracepción de emergencia, como la pastilla del día después, el acceso a la ejecución del aborto terapéutico en los hospitales públicos del país y la aplicación de la técnica de Fertilización In Vitro (FIV), entre otros (Zegers, Dickens, y Dughman 2014).

En el marco de esta cultura política conservadora, seguidamente se expone la convocatoria y la configuración de la manifestación $A$ mis hijos los educo yo.

\section{La convocatoria}

Organizaciones de corte evangélico convocaron a una manifestación que se realizó el sábado 22 de julio de 2017, en la Plaza de la Democracia, en la ciudad de San José, Costa Rica, bajo el lema A mis hijos los educo yo. La manifestación se denominó Magna Concentración por la Familia Costarricense, en contra de la educación sexual que impartiría el MEP, bajo el Programa de Estudio de Afectividad y Sexualidad Integral (Ministerio de Educación Pública (MEP) 2017).

Las imágenes que se presentan seguidamente son las que circularon por redes sociales, en particular, en el evento publicitado en Facebook denominado Concentración por la Familia Costarricense. Como se observa, las imágenes reproducen familias tradicionales, en el sentido de que representa una familia conformada por padre, madre, hijo e hija. 


\section{Imagen 1}

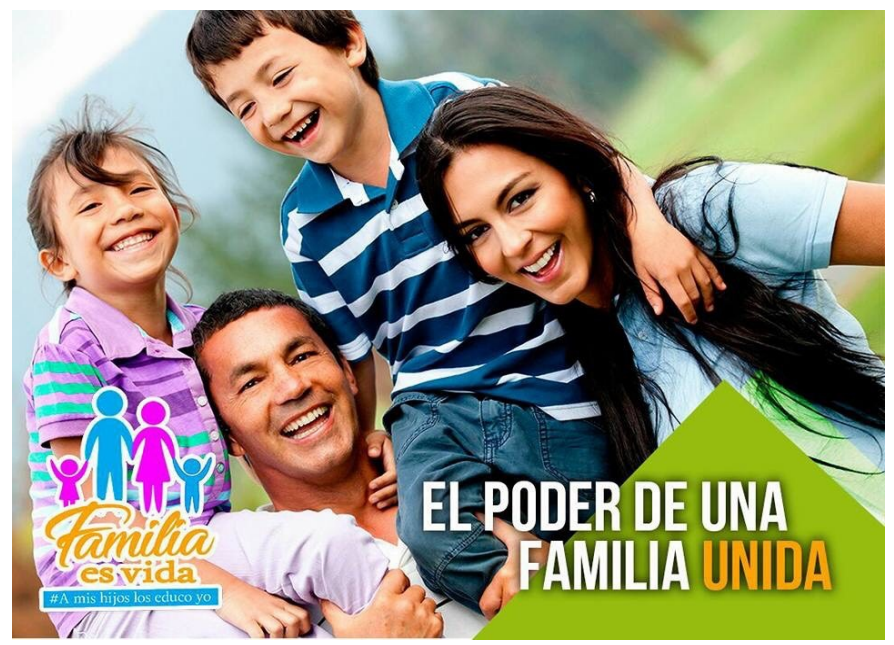

Fuente: Facebook Concentración por la Familia Costarricense, 2017

Las imágenes 2 y 3 representan la diversidad étnica de las familias, más no la diversidad sexual, dado que mantienen, al decir de Fernández, la lógica atributiva, binaria y jerárquica de las sexualidades. En estas imágenes se reproduce el modelo tradicional de la familia, con parejas heterosexuales y sus respectivos hijos e hijas.

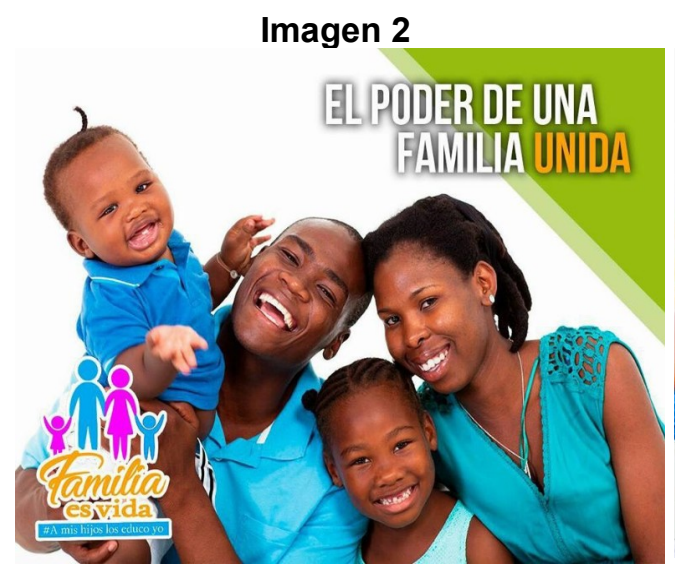

Fuente: Facebook Concentración por la Familia Costarricense, 2017

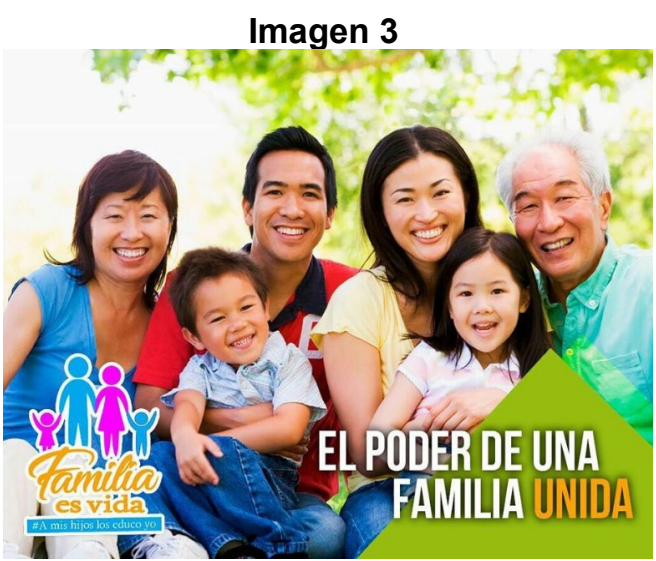

Fuente: Facebook Concentración por la Familia Costarricense, 2017

La imagen 4 muestra una pareja, que, si bien no tiene hijos, eventualmente los tendrá, dado que el mensaje que se reproduce posiciona el derecho del 
niño a una figura paterna y materna. El niño no nacido forma parte fundamental del mensaje que se reproduce en la imagen.

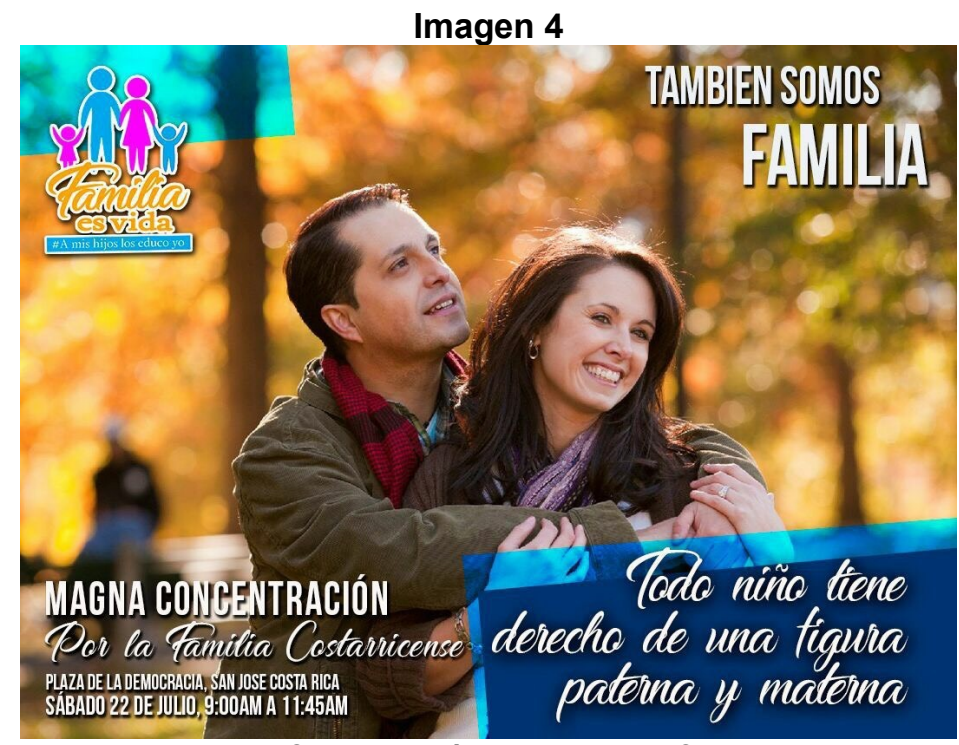

Fuente: Facebook Concentración por la Familia Costarricense, 2017

\section{La manifestación}

El llamado a la Magna Concentración por la Familia Costarricense se hizo para el sábado 22 de julio de 2017, en la Plaza de la Democracia. Debido al clima, que amenazaba con una lluvia temprana, las personas convocadas no se hicieron presentes desde primeras horas de la mañana. El espacio estaba dispuesto con una tarima sobre la Avenida Segunda, en la que los pastores evangélicos expusieron sus posicionamientos, algunos de ellos conocidos por su presencia en la televisión nacional y en redes sociales, como Sixto Porras del programa Enfoque a la Familia. También participaron conferencistas presentadas por su condición de profesionales, lo que fue el caso de una profesional en psicología. El discurso pronunciado por Sixto Porras el día de la manifestación se encuentra disponible en su blog (Porras 2017). En la imagen 5 se puede observar el inicio de la concentración en la Plaza de la Democracia. 
Imagen 5. Manifestación A mis hijos los educo yo



Reproducciones hechas en un reportaje periodístico publicado en La Nación mostraron algunos de los argumentos brindados por las personas que se presentaron en la manifestación. Algunas de las personas consultadas por este medio señalaron:

"Creemos en lo que dice la Biblia: varón y hembra los creó, y que la educación de nuestros hijos está en nosotros como padres, y que el MEP no debe meterse en esa parte. No estamos en contra de la educación sexual pero creemos que es en el seno de la familia", expresó Mauricio Vargas, vecino de Heredia" (Chinchilla 2017).

Otra de las personas consultadas por el medio señaló: “"El problema es que no nos están respetando nuestros pensamientos y no queremos que se inculque que son normales cosas que no lo son", dijo Salas" (Chinchilla 2017).

Las reproducciones presentadas en la prensa concuerdan con los mensajes que se presentan en la fotografía 6 . En esta imagen se observan mantas en 
donde se representa a La Familia, con padre, madre e hijo o hija. Esta se define como una entidad articulada por leyes divinas y la palabra de Dios. En este escenario, el enfrentamiento que las familias convocadas establecen con el Estado costarricense se da por el tipo de jerarquía de mando que debe seguirse, que en este caso corresponde a las leyes de Dios, y no a las disposiciones estatales.



Fotografía Sindy Mora Solano. 22 de julio de 2017

Como se señaló anteriormente, la consigna $A$ mis hijos los educo yo se acompañó con la frase Con mis hijos no te metas, también presente en las pancartas de algunas de las personas que se presentaron a la manifestación, como se observa en la imagen 7. En redes sociales, ambas frases se utilizaron con la etiqueta correspondiente: \#AMisHijosLosEducoYo y \#ConMisHijosNoTeMetas. 


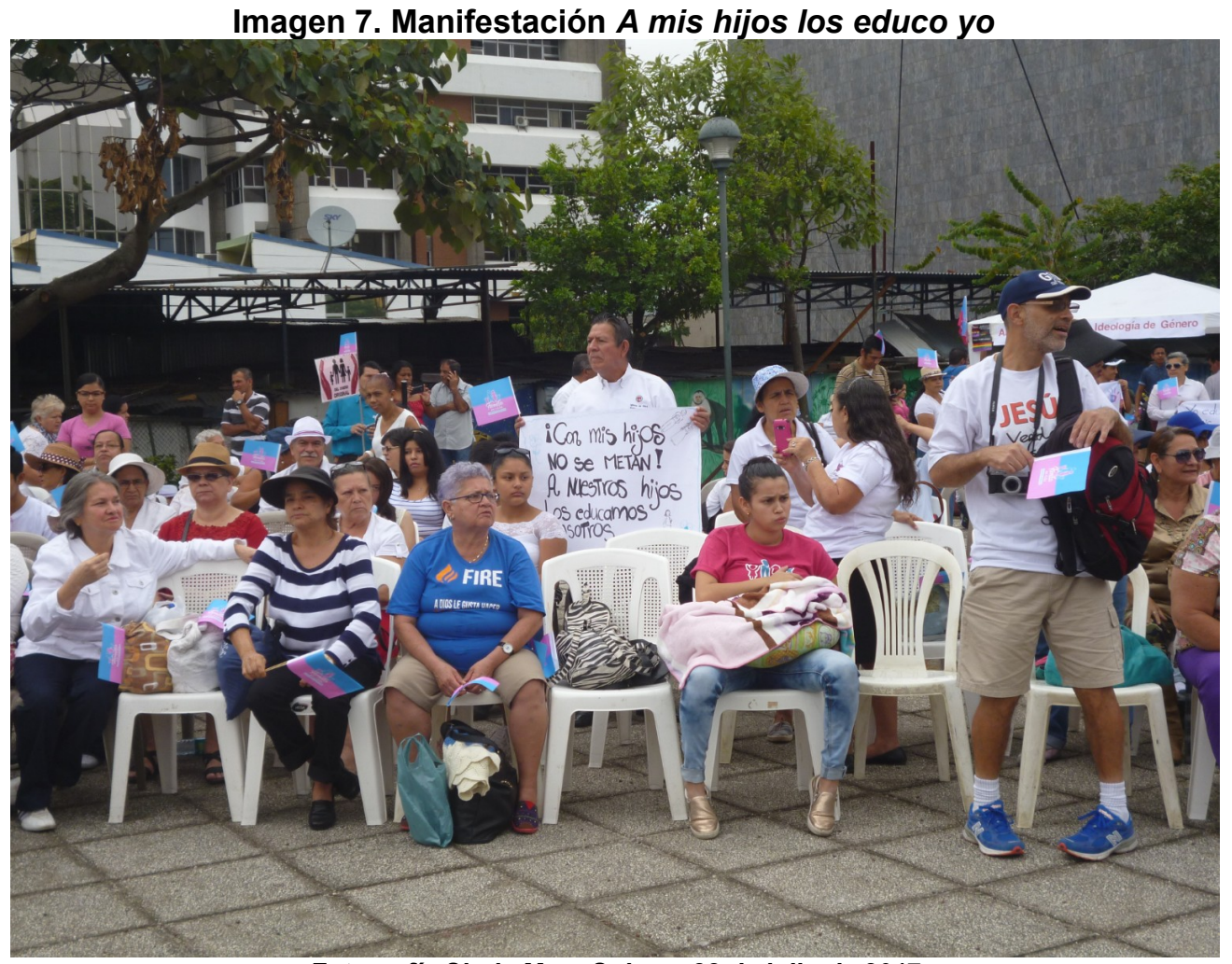

Fotografía Sindy Mora Solano. 22 de julio de 2017

La articulación familiar a partir de una jerarquía de mando divina y eclesiástica supone el seguimiento de un diseño original de familia que, de acuerdo con la información recabada en distintas pancartas expuestas en la manifestación, se encuentra establecido en los textos bíblicos. Al respecto, en la imagen 8 se evidencia la centralidad de estos textos, en donde se indica "CREÓ DIOS AL HOMBRE A SU IMAGEN. A IMAGEN DE DIOS LO CREÓ. VARÓN Y HEMBRA LO CREÓ. GN. 1:27". Todas estas mantas eran sostenidas por personas menores de edad.

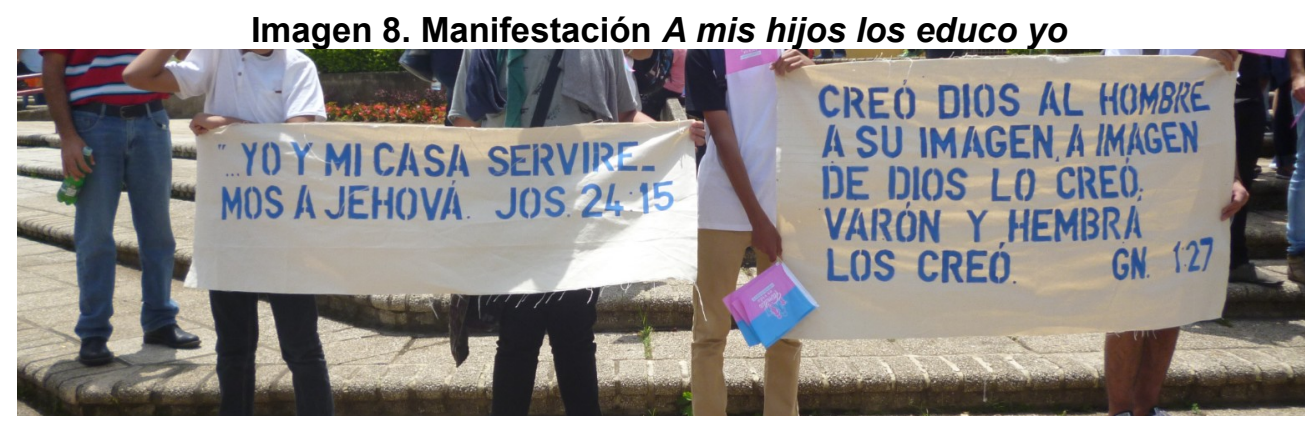

Fotografía Sindy Mora Solano. 22 de julio de 2017 
A pesar de que hasta este momento se han reproducido imágenes en donde se presentan pancartas o mantas hechas a mano, es pertinente subrayar que el día de la manifestación fue posible observar que la mayor parte de las personas tenían a su disposición banderas otorgadas por la organización de la actividad, como se reproduce en la imagen 9.

Este tipo de manifestaciones, producidas de manera industrial en sus iconografías, símbolos y mensajes, dan cuenta del limitado grado de autonomía que pueden tener sus participantes con el fin de construir y reclamar, con sus propias palabras, las reivindicaciones que les movilizan. De la misma manera, es importante señalar que la organización tenía camisetas para la venta con los mismos colores de las banderas otorgadas de manera gratuita: celeste para niños y hombres, rosado para niñas y mujeres y blanco para pastores.

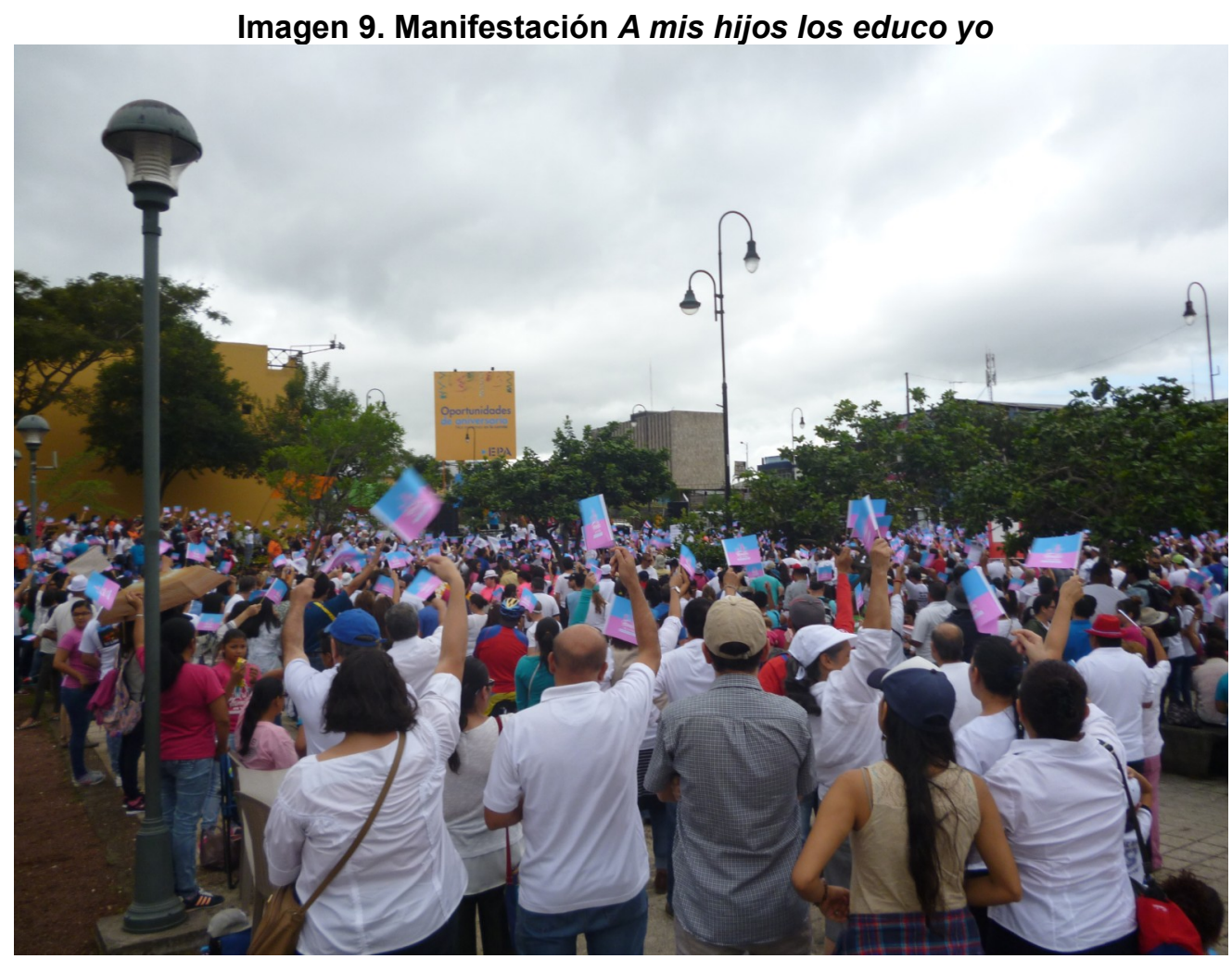

Fotografía Sindy Mora Solano. 22 de julio de 2017

La participación en la manifestación permitió evidenciar las formas en las que se encuentran el discurso religioso con las matrices nacionalistas. Por ejemplo, en la actividad se cantaron himnos nacionales, como el Himno Nacional de Costa Rica y el Himno Patriótico del 15 de setiembre, en donde la defensa de la familia se presentó como un valor patriótico y cívico, dado que la familia 
que se defiende es la costarricense, como señaló anteriormente. Es decir, mediante el discurso emitido por las personas que se presentaron en la tarima se hizo un llamado a las familias nacionales, dado que este no estaba dirigido a familias provenientes de otras naciones. Como señaló la psicóloga que estuvo presente en la tarima, la educación sexual debe basarse en "los principios éticos cristianos costarricenses"1 e, incluso, en la actividad se denominó a los representantes del MEP con la palabra "filibusteros", ${ }^{2}$ ya que estos habían propuesto la ideología de género como principio articulador de la política sexual impulsada por este ministerio.

Uno de los elementos relevantes que se presentó en el momento de la ora-

1. Información obtenida en la manifestación, disponible en las notas de campo.

2. Información obtenida en la manifestación, disponible en las notas de campo. ción fue el que posicionó la pregunta de si los grupos evangélicos son intolerantes, como reconocen que se les denomina. La respuesta fue: "no es intolerancia, es un grito de amor". ${ }^{3}$ De la misma manera, ante las acusaciones que vinculan a los grupos evangélicos con los discursos de odio, en esta manifestación fue planteada la pregunta por el amor hacia los homosexuales y la respuesta obtenida fue la siguiente: "Y tanto les amamos que queremos que se conviertan para que encuentren su verdadero placer". 4

En esta manifestación se puede observar cómo la lógica atributiva, binaria y

3. Información obtenida en la manifestación, disponible en las notas de campo. jerárquica de las sexualidades, de la que habla Fernández, se instituyó como manifestación, disponible en el discurso aglutinador de este movimiento. Desde esta perspectiva, la educación sexual debe respetar el orden Dios-iglesia-familia, en donde el Estado no tiene ninguna cabida. No está de más recordar el género de Dios y de quienes dominan los espacios eclesiales y familiares, que es el género masculino.

Con el apoyo del diputado Fabricio Alvarado, del Partido Restauración Nacional (PRN), en la prensa se reprodujeron los principales ejes de la oposición de los grupos convocados a la manifestación: "No permitamos que nos impongan la ideología de género y que adoctrinen a nuestros hijos. Defendamos la vida, la familia, el matrimonio entre hombre y mujer, y la libertad religiosa" (Solano 2017).

La denominada ideología de género es la expresión con la que se intenta rebajar el estatus de las teorías feministas y los estudios de género, denigrándolas por su carácter ideológico. Como se observa en la imagen 10, la estrategia seguida por los actores políticos conservadores ha sido la de deslegitimar las teorías feministas y los estudios de género denominándolas ideologías. 


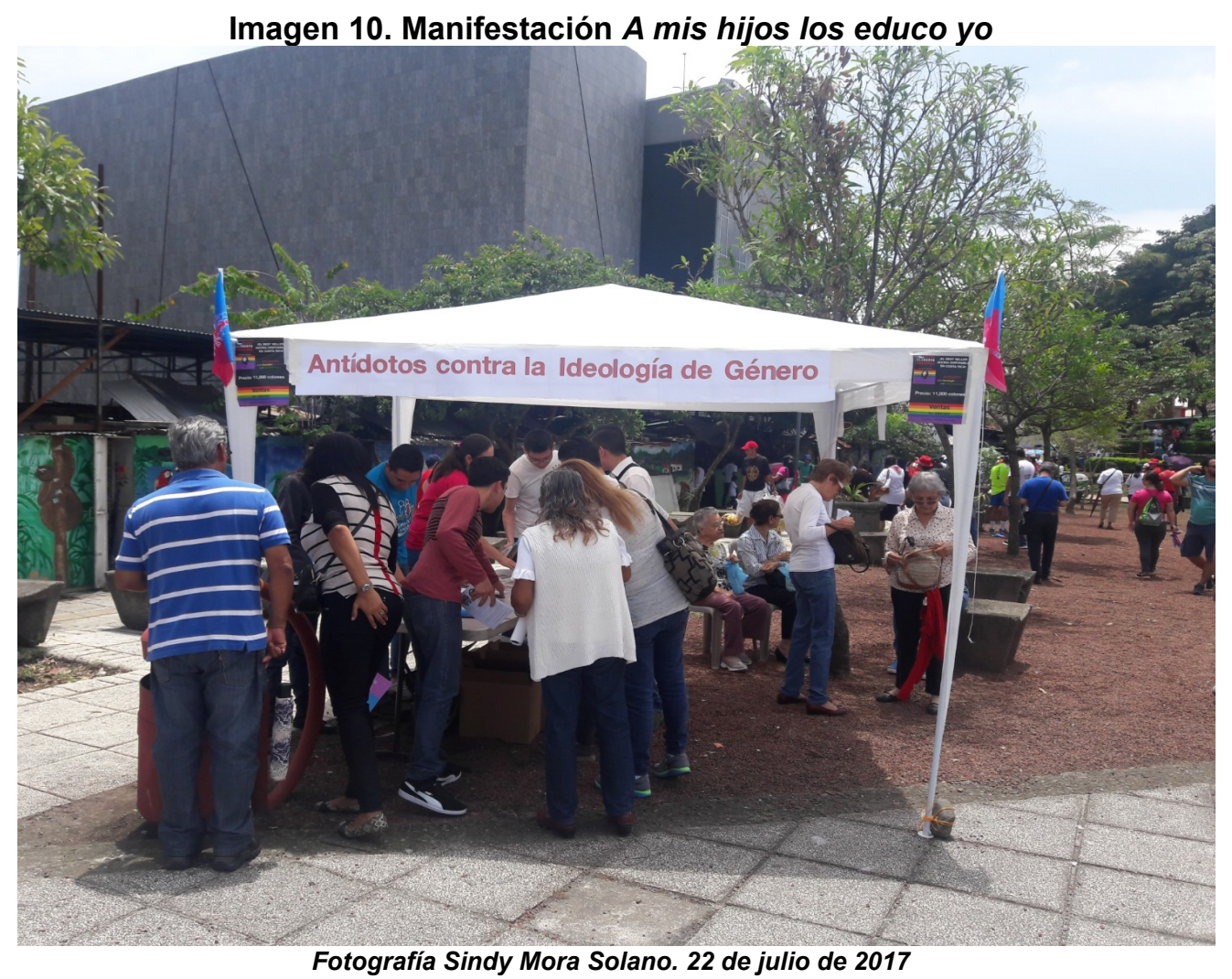

En ese sentido, es importante comprender el juego entre el lenguaje científico y el no científico, para comprender la estrategia utilizada por estos actores. Antídoto es una palabra que se inscribe en el lenguaje de la ciencia. Vender antídotos contra la ideología de género, como se realizó en la manifestación en estudio, responde a una estrategia en la que los actores políticos conservadores se posicionaron como los poseedores de la cura para un veneno o sustancia que enferma o contamina un determinado cuerpo. En la lógica de esta manifestación, el veneno contra que el que se deben aplicar este tipo de antídotos es la educación sexual.

En este sentido, los actores políticos conservadores proyectan en las teorías feministas y los estudios de género el carácter ideológico, del que supuestamente ellos se encuentran librados, así como posicionan la idea de que los actores conservadores tienen de su lado a la ciencia y a los antídotos contra la ideología de género. Valga señalar que parte de los discursos registrados en la manifestación tenían como fin rechazar las acusaciones que sitúan a estos actores políticos en la ignorancia o en la negación de los conocimientos científicos. Por ello, en algunos de los momentos de agitación en la actividad, en donde alguna persona tenía el uso de la palabra, se mencionaron frases como las siguientes: "nos dicen ignorantes, pero creemos en la ciencia, cree- 
mos en la biología. A mis hijos los educo yo". ${ }^{5}$ Ante estas frases, el público respondía aplaudiendo y gritando eufóricamente.

Ahora bien, ¿cuál fue el antídoto contra la ideología de género que se vendió en la manifestación $A$ mis hijos los educo yo? Este era el texto El libro negro de la nueva izquierda, medicamento eficaz en la lucha contra la ideología de género. Por ello, a manera de hipótesis y en el marco de los conflictos que se suscitaron después con la Universidad Nacional de Costa Rica, en donde esta fue acusada de censurar la presentación del libro (La Nación 2017) y, posteriormente, sancionada por la Sala IV (Lara 2017), es importante señalar que si bien los actores políticos conservadores del país tienen asegurada una legitimidad político-parlamentaria y logran movilizar colectivos a las calles con el repertorio de las acciones colectivas de protesta, lo que colabora con la construcción de dicha legitimidad, estas agrupaciones reconocen que el recurso del que carecen es de la legitimidad científica y académica, al apropiarse de las acusaciones de ignorancia o acientificidad que se emiten en su contra. De allí que se vuelva trascendental la disputa por los espacios universitarios.

En ese sentido, a partir de la participación y recopilación de información en esta protesta social, en donde se hicieron claros llamados a tomar las riendas de la política del país, ${ }^{6}$ la gran disputa de los actores políticos conservadores, disputa que en ocasiones parece una herida política (Porras 2017), es con los centros de producción de pensamiento, en donde se produce investigación con perspectiva feminista y de género. Esta tesis ha sido reafirmada por otras investigaciones, las que han llegado a esta conclusión mediante otros tipos de análisis (Arguedas 2020; Arce 2017; Burneo 2018; Meneses 2019).
5. Información obtenida en la manifestación, disponible en las notas de campo.
6. Información obtenida en la manifestación, disponible en las notas de campo.

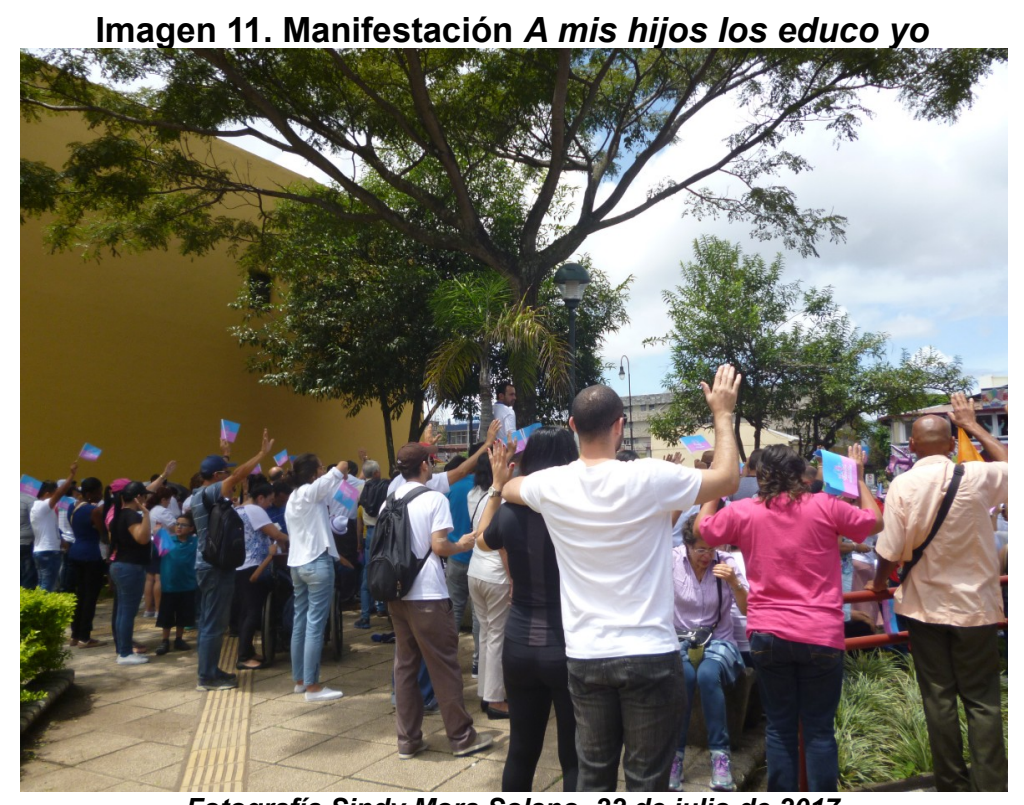

Fotografía Sindy Mora Solano. 22 de julio de 2017 
Las imágenes 11 y 12 muestran el fin de la concentración, que culminó con una oración y un concierto.

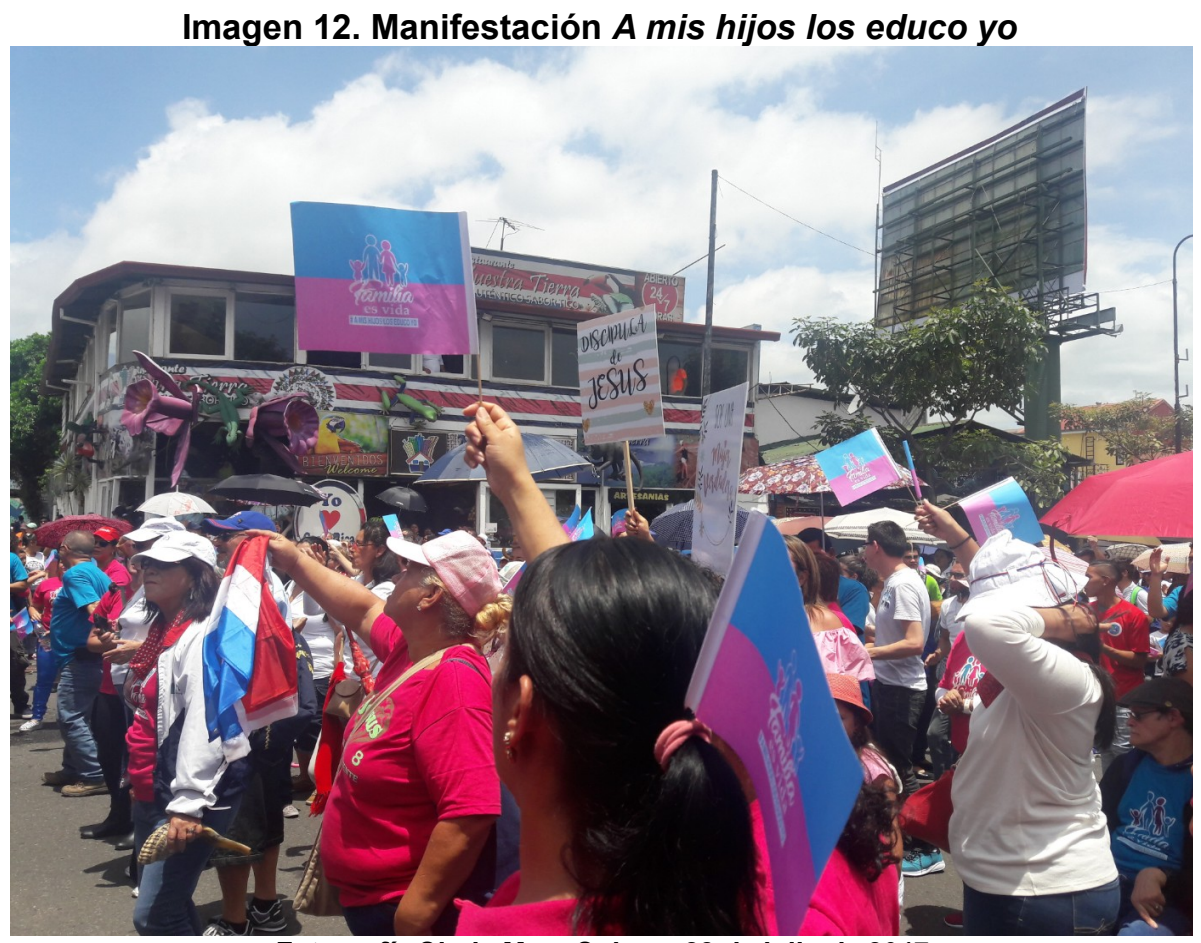

Fotografía Sindy Mora Solano. 22 de julio de 2017

Las imágenes presentadas evidencian la articulación de un movimiento conservador, en donde se posiciona con fuerza la lógica atributiva, binaria y jerárquica de las sexualidades y en el cual las corporeidades no pueden salirse del molde establecido por unas manos diseñadoras superiores a lo humano, que delinean un proyecto sexual, reproductivo y familiar definido como un diseño original, como se muestra en la imagen 13. Este diseño original, cobijado por manos superiores, es heterosexual y con fines reproductivos. Por ello, salirse del molde de la heteronormatividad, como se reprodujo en los cuestionamientos planteados por Judith Butler, implica salirse de una condición humana sumisa a los designios del diseño original. 
Imagen 13. Manifestación A mis hijos los educo yo

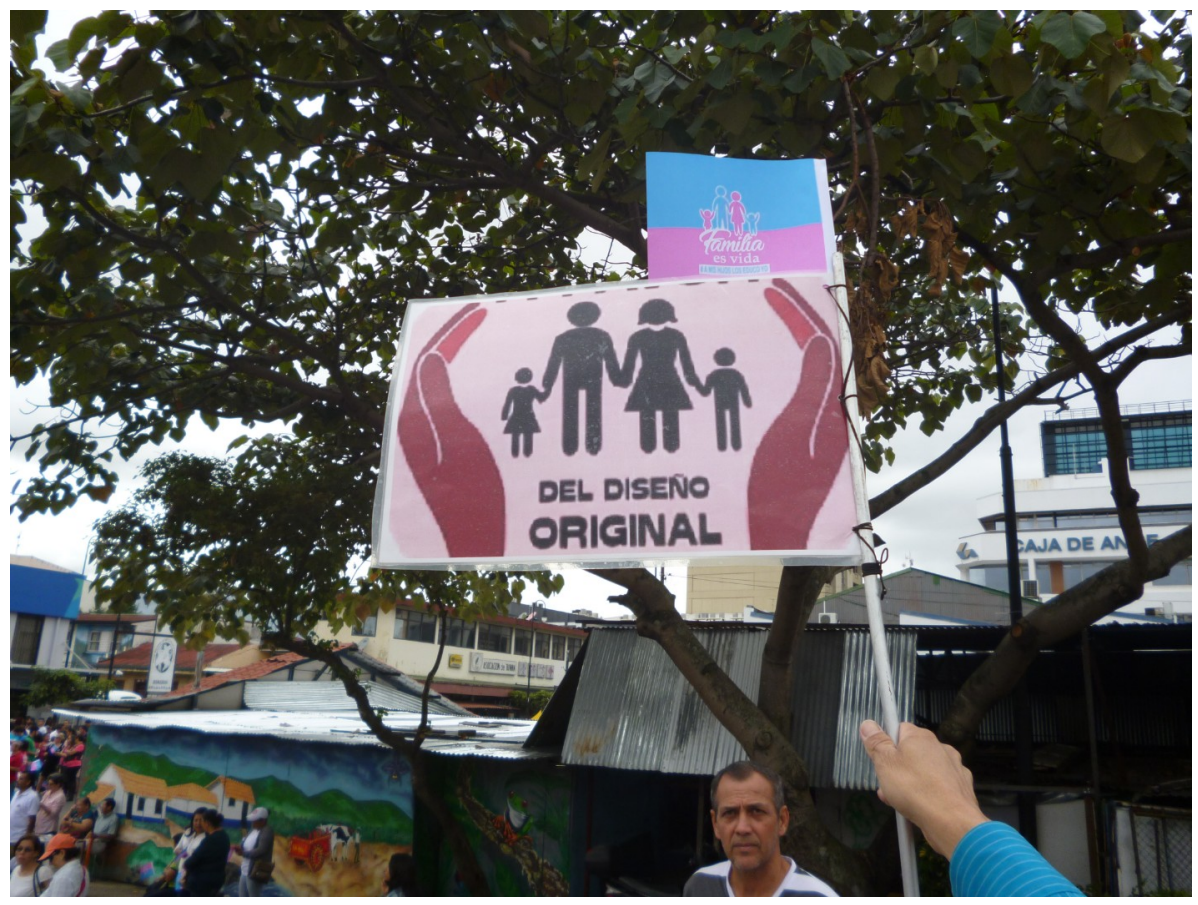

Fotografía Sindy Mora Solano. 22 de julio de 2017

\section{Reflexiones finales}

En este trabajo se ha expuesto un análisis de la manifestación $A$ mis hijos los educo yo, entendiéndola como una expresión de un movimiento conservador transnacional, con un claro proyecto, que ejecutó un despliegue de recursos políticos como las imágenes, las banderas, los discursos, las oraciones, la música, la presencia de personalidades de organizaciones como Enfoque a la Familia, el conocimiento psicológico, la venta de camisetas y del antídoto contra la ideología de género.

En estas movilizaciones conservadoras ha sido fundamental la difusión de imágenes de familias que, si bien podrían denominarse étnicamente diversas, son sexualmente homogéneas, ya que se encuentran inscritas en la lógica atributiva, binaria y jerárquica de las sexualidades, de acuerdo con lo planteado por Ana María Fernández. En la manifestación, la palabra estuvo contralada por reconocidas figuras de la televisión y de las redes sociales, en particular, del programa Enfoque a la familia, así como por discursos emitidos por profesionales en psicología.

A pesar de que se mostraron imágenes de pancartas y mantas producidas manualmente, este movimiento conservador logró movilizar sus recursos 
económicos y políticos, lo que se expresó en una iconografía producida en serie, con colores y discursos homogéneos y homogenizantes. Como lo señala la literatura producida en la región sobre este tema, estas manifestaciones se realizaron en distintos países latinoamericanos, con discursos, simbologías y recursos iconográficos reproducidos en camisetas y banderas, idénticos para todos los países.

Con la disposición de estos recursos, los grupos políticos conservadores movilizados propusieron la reproducción de la lógica atributiva, binaria y jerárquica de las sexualidades, la que supone la defensa de un diseño original de familia que niega la posibilidad de otras corporeidades, otras sexualidades y otras organizaciones familiares que no tengan como fin la reproducción. Este diseño de familia ha sido establecido y reproducido gracias al saber de los textos bíblicos, de los pastores eclesiásticos y de los padres de familia, en donde lo que se reproduce es una subjetividad política de la sumisión, que tiene que ser acatada por quienes integran las familias, pero, fundamentalmente, por los hijos e hijas.

Esta manifestación, realizada antes de la declaratoria oficial del inicio de la campaña político-electoral costarricense del 2017-2018, sentó un precedente en cuanto a los argumentos y discursos políticos que se posicionarían fuertemente en las elecciones nacionales del año 2018.

\section{Referencias bibliográficas}

Arce, Leonardo. 2017. «La “ideología de género” y la embestida mediática: crítica de un discurso falaz». Revista Nomadías, n. ${ }^{\circ}$ 24: 1-20.

Arguedas, Gabriela. 2010. «El (aún) tortuoso camino hacia la emancipación: fundamentalismos religiosos, los derechos humanos de grupos históricamente oprimidos y la lucha por un Estado Laico en Costa Rica». Anuario Centro de Investigaciones y Estudios Políticos, 50-65.

—. 2020. «Políticas antigénero en América Latina: Costa Rica». Observatorio de Sexualidad y Política (SPW). 
Auyero, Javier. 2002. La protesta. Retratos de la beligerancia popular en la Argentina democrática. Libros del Rojas, Universidad de Buenos Aires. Argentina.

_ 2004. Vidas Beligerantes. Dos mujeres argentinas, dos protestas y la búsqueda de reconocimiento. Argentina: Editorial de la Universidad Nacional de Quilmes.

Avendaño, Manuel. 2017. «Ministra de Educación: Programas de sexualidad no promueven una 'ideología de género`». AmeliaRueda.com, 26 de agosto de 2017. https://www.ameliarueda.com/nota/ministra-mepprogramas-sexualidad-no-promueven-ideologia-genero.

Burneo, Cristina. 2018. «Ecuador: La fabricación de la "ideología de género"». En Develando la retórica del miedo de los fundamentalismos. La campaña "Con mis hijos no te metas» en Colombia, Ecuador y Perú. Perú: Flora Tristán. Centro de la Mujer Peruana.

Butler, Judith. 2007. El género en disputa. El feminismo y la subversión de la identidad. Barcelona: Paidós Editorial.

Chinchilla, Sofía. 2017. «Manifestantes cristianos exigen cancelar lecciones de sexualidad en los colegios». La Nación, 22 de julio de 2017. http:// www.nacion.com/nacional/educacion/Manifestantes-cristianoslecciones-sexualidad-colegios_0_1647435267.html. 
Córdova, Julio. 2014. «Viejas y nuevas derechas religiosas en América Latina: los evangélicos como factor político». Nueva Sociedad, 11223.

Cunha, Magali. 2017. «Construções imaginárias sobre a categoria "Gênero" no contexto do conservadorismo político religioso no Brasil dos anos 2010». Perspectiva Teologica 49 (2): 253-76.

Da Silva, Erineusa Maria, Elda Alvarenga, Fábio Luiz Alves De Amorim, y Eliza Bartolozzi Ferreira. 2018. «A “ideologia De Gênero” e A “escola Sem Partido": faces de uma mesma moeda em ações políticas conservadoras no Brasil e no Espírito Santo». Inter - Ação 43 (3): 61531.

De Carvalho, Fabiana Aparecida, y Alexandre Luiz Polizel. 2018. «O Escola sem Partido e o discurso sobre uma suposta "ideologia de gênero"». Inter - Ação 43 (2): 600-614.

Díaz, José. 2017. «La agenda religiosa-conservadora en el discurso político durante la campaña electoral en Costa Rica (2013-2014)». Revista de Ciencias Sociales III (157): 65-81.

Fernández, Ana María. 2009. Las lógicas sexuales: amor, política y violencias. Buenos Aires: Nueva Visión.

Fontelas, Maria José. 2015. «A “ideologia de gênero” na discussão do PNE: a intervenção da hierarquia católica». HORIZONTE: Revista de Estudos de Teologia e Ciências da Religião 13 (39): 1237-60. 
Fuentes, Laura. 2014. «El cristianismo en la matriz política del Estado: laicidad y autonomía reproductiva en Costa Rica y Nicaragua». Anuario de Estudios Centroamericanos, 11-36.

— 2018. «Politización evangélica en Costa Rica en torno a la agenda "provida": ¿Obra y gracia del Espíritu Santo?» Revista Rupturas 9 (1): 85-106.

González, Ana Cristina, y Laura Castro. 2018. «Colombia: Educación sexual, diversidad y paz: el entramado de la "ideología de género"». En Develando la retórica del miedo de los fundamentalismos. La campaña «Con mis hijos no te metas» en Colombia, Ecuador y Perú. Perú: Flora Tristán. Centro de la Mujer Peruana.

González, Ana Cristina, Laura Castro, Cristina Burneo, Angélica Motta, y Oscar Amat y León. 2018. Develando la retórica del miedo de los fundamentalismos. La campaña "Con mis hijos no te metas» en Colombia, Ecuador y Perú. Perú: Flora Tristán. Centro de la Mujer Peruana.

Jung Mo Sung. 2015. «Prosperidade sim, família homossexual, não! A nova classe média evangélica». Psicologia USP 26 (1): 43-51.

La Nación. 2017. «Autores acusan a la UNA de "censura" tras suspender presentación de "El libro Negro de la nueva izquierda"». La Nación, 31 de agosto de 2017. http://www.nacion.com/el-pais/politica/autoresacusan-a-la-una-de-censura-tras-suspender-presentacion-de-el-libro- 
negro-de-la-nueva-izquierda/NRV2B4T35JHKRKORTAIDWDTSZY/ story/.

Lara, Juan Fernando. 2017. «Sala IV condena a rector de la UNA por impedir divulgación de libro». La Nación, 23 de octubre de 2017. http://www.nacion.com/el-pais/sala-iv-condena-a-rector-de-la-una-porimpedir-divulgacion-de-libro/DIYBQSRIWBAUHBDHPWVOZIRS4Q/ story/.

Lenine, Enzo, y Locarine Oncampo. 2020. «Recuperando a justiça de gênero e a África nas Conferências Mundiais da Mulher». Meridiano 47 Boletim de Análise de Conjuntura em Relações Internacionais 21: 119. https://doi.org/10.20889/M47e21009.

McCarthy, John, y Mayer Zald. 1977. «Resource Mobilization and Social Movements: A Partial Theory». American Journal of Sociology, 121241.

Meneses, Daniela. 2019. «Con Mis Hijos No Te Metas: un estudio de discurso y poder en un grupo de Facebook peruano opuesto a la "ideología de género"». Antropológica (02549212) 37 (42): 129-54.

Ministerio de Educación Pública (MEP). 2017. «Programa de Estudio de Afectividad y Sexualidad Integral».

Ministerio de Salud. 2016. II Encuesta Nacional de Salud Sexual y Reproductiva Costa Rica 2015. San José: UNFPA.

Morán Faúndes, José Manuel. 2019. «The geopolitics of moral panic: The influence of Argentinian neo-conservatism in the genesis of the 
discourse of 'gender ideology'». International Sociology 34 (4): 40217.

Pleyers, Geoffrey. 2019. «Pensar los actores conservadores y capitalistas como movimientos sociales». Revista de Estudios Sociales 67: 11623.

Porras, Sixto. 2017. « ¡A mis hijos los educo yo!» Blog de Sixto Porras (blog). 23 de agosto de 2017. https://www.enfoquealafamilia.com/crianza/amis-hijos-los-educo-yo/.

Portantiolo Maia, César, Maíra Bittencourt, y Donizete Rodrigues. 2017. «Rede "Ideologizada"? Gênero, participação social e convicções religiosas em publicações brasileiras no Facebook». Espaço e Cultura, n. ${ }^{\circ} 42: 26-43$.

Quesada, Carolina. 2012. «Familia y heteronormatividad: acontecimientos históricos y la doctrina sexual de la Iglesia Católica en Costa Rica». Anuario de Estudios Centroamericanos, 305-28.

Ribeiro, Edméia. 2019. «"Ideologia de gênero”: ofensiva reacionária, pânico e cruzada moral no México (2016)». Antíteses 12 (24): 488-516.

Romancini, Richard. 2018. «Do "Kit Gay" ao "Monitor da Doutrinação": a reação conservadora no Brasil». Contracampo 37 (2): 87-108.

Santos Serejo, Elias, y Danila Cal. 2021. «Em defesa de que famílias? Bolsonarismo, pânico moral e o protagonismo da categoria família nas eleições de 2018». Revista Eptic 23 (1): 27-46. 
Solano, Johel. 2017. «Anuncian marcha por la familia y contra educación sexual». CRhoy.com, 21 de julio de 2017. https://www.crhoy.com/nacionales/anuncian-marcha-por-la-familia-ycontra-educacion-sexual/.

Zegers, Fernando, Bernard Dickens, y Sandra Dughman. 2014. «El derecho humano a la fecundación in vitro». Revista Chilena de Obstetricia y Ginecología 3 (79): 229-35.

\section{Imágenes y fotografías}

Concentración por la Familia Costarricense. Imágenes de convocatoria a la manifestación A mis hijos los educo yo. San José, 22 de julio de 2017.

Mora, Sindy. Manifestación pública A mis hijos los educo yo. San José, 22 de julio de 2017. 